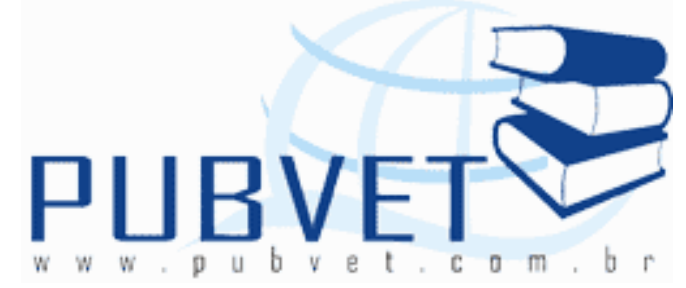

PUBVET, Publicações em Medicina Veterinária e Zootecnia.

\title{
Utilização de soro de queijo in natura no aleitamento de bezerros: uma alternativa viável
}

Renata Nayhara de Lima ${ }^{1}$, Andrezza Kyarelle Bezerra de Moura ${ }^{1}$, Patrícia de Oliveira Lima ${ }^{2}$, Jacinara Hody Gurgel de Morais ${ }^{3}$, Maria Vivianne Freitas Gomes de Miranda ${ }^{1}$, Katia Tatiana de Lima Lopes ${ }^{4}$

${ }_{1}^{1}$ Mestranda do Programa de Pós-graduação em Ciência Animal - UFERSA

${ }^{2}$ Profa. D.Sc. Departamento de Ciências Animais - UFERSA

${ }^{3}$ Mestre em Produção Animal

${ }^{4}$ Graduanda em Zootecnia - UFERSA

\section{Resumo}

O custo com alimentação dentro de um sistema de produção é o que mais onera atividade, com isso a utilização de alimentos alternativos está sendo bastante difundida. No aleitamento de bezerros o soro de queijo esta se tornando uma alternativa bastante viável, pois o mesmo apresenta proteínas de alto valor biológico e sua utilização reduz os poluentes no meio ambiente, no entanto não deve ser feita a substituição total do leite pelo soro de queijo, por não apresentar os nutrientes necessários para garantir sozinho o desenvolvimento dos animais nessa fase. A geração dessa tecnologia permitirá o aproveitamento de soro de queijo pelos sistemas de produção e pode trazer ainda redução no impacto ambiental, pois esse resíduo dos laticínios é pouco aproveitado, sendo descartado no ambiente, principalmente quando se trata 
de pequenos e médios laticínios que não dispõem de equipamentos para reaproveitá-lo na fabricação de outros derivados ou destinando-o à indústria da alimentação humana.

\title{
Use in natura serum cheese for calves in breast-feeding: an viable alternative
}

\begin{abstract}
The cost of feeding within a production system is the most onerous activity, thus the use of alternative foods is widespread. In breast-feeding the calves whey is becoming a very feasible alternative because it presents a high biological value proteins and their use reduces pollutants in the environment, but should not be the complete replacement of milk by whey by not showing the necessary nutrients to ensure the development of animals alone in this phase. The generation of this technology will allow the use of whey for production systems and can bring further reduction in environmental impact because the residue of the dairy is little used, and discarded in the environment, especially when it comes to small and medium dairy products that do not have equipment for reuses it in manufacturing or other derivatives destined him for the food industry.
\end{abstract}

\section{INTRODUÇÃO}

Os custos de criação de animais de reposição representam entre $15 \%$ e $20 \%$ dos custos totais na maioria das fazendas leiteiras, sendo que $50 \%$ a $60 \%$ destes gastos advêm da alimentação das bezerras e novilhas (DAVIS; DRACKLEY, 1998). A criação de bezerros, em regime de aleitamento natural ou artificial, é caracterizada por alto custo, sendo que até $80 \%$ dos gastos é devido ao leite integral (LIZIERE; CAMPOS, 1992), isso encarece o sistema de produção de leite, já que eles são improdutivos até chegarem à primeira 
parição e é necessário em torno de duas lactações para se recuperar o capital investido (FARIA, 1995).

O avanço das técnicas de alimentação e manejo na pecuária leiteira, principalmente relacionada com a criação de bezerros, tem levado os criadores a buscarem a racionalização da produção de bezerros, empregando métodos eficientes e econômicos que reflitam no aumento da disponibilidade de carne e na maior oferta de leite para o mercado (TEIXEIRA et al., 2000). O uso de sucedâneos de leite é prática comum durante a maior parte ou todo o período de dieta líquida das bezerras de $70 \%$ das propriedades norte-americanas (HEINRICHS; JONES, 2003). No Brasil a utilização ainda é restrita, sendo que a maioria dos trabalhos iniciais desenvolvidos apresentou alto índice de mortalidade devido à diarréia, provavelmente relacionada à presença de ingredientes contendo fatores antinutricionais (THALER NETO et al., 2008).

$\mathrm{O}$ uso desses produtos permite aos produtores a venda de maior volume de leite, com conseqüente aumento da disponibilidade para a indústria e para a alimentação humana (FONTES et al., 2006). Entretanto, a utilização de produtos desta natureza demonstra, em muitos casos, disparidades no desempenho dos animais, principalmente associados com alimentos de menor aproveitamento, gerando diminuição no ganho de peso e elevação do gasto com medicamentos, quando comparados ao leite integral (VASCONCELOS, 1996). Estes problemas parecem estar relacionados ao excesso de fibra e amido, ao tipo e à inadequada incorporação de gordura além da utilização de fontes protéicas de baixo aproveitamento ou que provocam transtornos digestivos nos bezerros (CAMPOS; LIZIEIRE, 1995).

Ou seja, o aumento da lucratividade do sistema de criação está na dependência direta das relações de custo/benefício dos produtos utilizados (FONTES et al., 2006). Assim, o estudo dos custos de produção fornece ao empresário um indicativo para a escolha dos processos produtivos a serem adotados e seguidos, visando apurar os melhores resultados econômicos (REIS, 1999). 


\section{CUSTO NA PRODUÇÃo DE LEITE}

O custo de produção de leite é o detalhamento de todas as despesas diretas e indiretas que devem ser controladas para que se possa obter, com exatidão, o quanto se está investindo e gastando para produzir (ANTUNES; ENGEL, 1999). Este constitui um elemento auxiliar na administração de qualquer empreendimento, sendo normalmente conceituado como a soma dos valores de todos os insumos e serviços empregados na produção de um determinado bem (CANZINI, 1999; YAMAGUCHI, 1999).

Para Hoffman et al. (1987) o termos custo, para fins de análise econômica, significa a compensação que os donos dos fatores de produção utilizados por uma empresa para produzir determinado bem devem receber para que eles continuem fornecendo esses fatores às empresas. Pelo estudo sistemático dos custos incorridos na produção do leite, pode o produtor (empresário) fixar diretrizes e corrigir distorções, possibilitando a sobrevivência do sistema de produção de leite em um mercado cada vez mais competitivo e exigente (LOPES; CARVALHO, 2000).

Segundo Salles et al. (2001) em sistemas de produção de bovinos leiteiros, assim como em outros sistemas, a busca pela eficiência na produção e o aumento da produtividade é uma necessidade crescente do produtor para a permanência na atividade. Nesse sistema a principal fonte de receita é a venda do leite, além da venda dos bezerros, do excedente de novilhas para reposição e de vacas descartadas para abate (CARDOSO et al., 2004).

A pecuária de leite é considerada atividade de baixa rentabilidade por apresentar altos custos de produção em relação aos preços de venda, baixa produtividade por animal e por área e pequenos volumes produzidos individualmente pelas unidades fundiárias produtoras, em sua maioria, familiares. Nesse aspecto, deve-se considerar que a venda de animais excedentes ou de descarte é a segunda grande receita de qualquer propriedade leiteira. Do plantel estimado de vacas do Brasil, pode-se esperar produção anual de 5,5 milhões de bezerros, que poderiam ser criados em 
sistemas diferenciados de produção para elevar a receita dessas propriedades e aumentar a produção de carne (ALMEIDA JR. et al., 2008).

\section{ASPECTOS TÉCNICOS DA CRIAÇÃo DE BEZERROS}

A criação de fêmeas jovens pode ter duas finalidades: reposição das matrizes do plantel ou comercialização dos animais. A criação de bezerras pode ser considerada como sendo o primeiro passo na exploração leiteira e seu sucesso depende em grande parte da maneira como é realizada (LUCCI, 1992). O estabelecimento de um sistema de cria e recria eficiente para as fêmeas em rebanhos leiteiros é um desafio para a maioria dos produtores. Se de um lado elas devem receber alimentação e manejo adequados para que possam atingir o peso ideal à primeira cobertura e iniciarem a sua vida produtiva o mais cedo possível, de outro lado está o fator econômico (CAMPOS; LIZIEIRE, 2000).

De acordo com Campos et al. (1993) a criação de bezerros de raças leiteiras é, provavelmente, a fase mais crítica, e determinante do futuro da exploração leiteira. Os bezerros são animais muito frágeis, pois eles têm uma baixa resistência às enfermidades e parasitas. Segundo Coelho (2005) os pontos mais importantes e críticos para a criação dos bezerros são: as instalações (maternidade e bezerreiro), o fornecimento do colostro, a cura do umbigo, o fornecimento da dieta líquida e o desenvolvimento do rúmen. De maneira geral, os sistemas criatórios visam apenas a produtividade e facilidade de manejo, onde as condições da criação confinada não permitem ao bezerro expressar seus comportamentos naturais, além de ocorrer monotonia ambiental, prejudicando seu bem-estar (KROHN, 2001).

De acordo com Bath et al. (1985) o sucesso de uma produção leiteira depende fundamentalmente de um correto manejo com os animais que irão incorporar o plantel. Os animais jovens quando adequadamente alimentados desenvolvem-se rapidamente, podendo chegar a sua fase adulta mais cedo. No entanto, a criação de bezerros eleva o custo da produção de leite, 
especialmente quando o leite integral é fornecido por longos períodos, ao invés de destinar-se ao consumo humano e transformar-se em receita para o produtor (ROCHA et al., 1999). Neste contexto, novilhas de reposição devem receber maior atenção, pois não possuem produção direta na geração de receita (SALLES et al., 2001).

\section{CONSIDERAÇÕES SOBRE O ALEITAMENTO DE BEZEERROS}

Segundo Lombardi et al. (1997) o leite representa em torno de $90 \%$ do custo de produção dos bezerros, dado que reforça a importância na redução da quantidade fornecida, reduzindo os custos na produção desses animais. Sem esquecer que a alimentação exclusiva a base de leite provoca 0 subdesenvolvimento do rúmen (KOLB et al., 1984).

Nos últimos anos pesquisadores ao redor do mundo tem intensificado esforços na busca por uma tecnologia capaz de permitir a diminuição dos custos da criação de bezerra com economia de leite e de mão-de-obra sem prejuízo ao desenvolvimento normal da bezerra até a condição de vaca em lactação (D 'AVILA, 2006).

Ao nascer, o bezerro comporta-se como um monogástrico com o estômago apresentando características diferentes do ruminante adulto, não sendo capaz de utilizar alimentos sólidos, tem reflexo para mamar e tem todas as condições fisiológicas e bioquímicas para utilizar o leite (CARVALHO et al., 2002). Segundo Oliveira (2007) o sistema digestivo do bezerro é, então, totalmente dependente dos nutrientes do leite, durante as primeiras semanas de idade.

O leite integral é o alimento natural usado na criação de terneiros, mas pode tornar-se caro. Assim, foram desenvolvidas alternativas que restringem seu uso como no caso do desaleitamento precoce ou o substituem, através da utilização dos sucedâneos lácteos, reduzindo o custo da alimentação e/ou disponibilizando mais leite para o consumo humano (BERMUDES; PEIXOTO, 1997). 
Devido aos altos valores biológico e econômico do leite integral, a sua substituição, na alimentação de bezerros, por um produto de menor custo e níveis nutricionais semelhantes tem constituído um desafio dentro dos sistemas de produção de ruminantes. Os níveis de substituição do leite in natura em sistemas de aleitamento estão intimamente agregados ao custo comparado do produto substituinte (MODESTO et al., 2002).

Além do custo, outros problemas necessitam ser contornados quando se procura substituir o leite por outro alimento, em idade precoce, tais como: ausência de sistemas enzimáticos capazes de hidrolisar outro carboidrato que não seja lactose; outros lipídeos que não sejam os da gordura do leite (ácidos graxos de cadeia curta); a necessidade fisiológica de uma proteína que, tal como a caseína, propicie a formação de um coágulo de boa consistência no abomaso, além da presença de fatores antinutricionais (DAVIS \& DRACKLEY, 1998).

Orskov (1990) relata ser possível substituir precocemente a proteína do leite por outras proteínas, apesar de que, tecnicamente, essa substituição seja difícil, pois quando a proteína láctea reage com os sucos estomacais forma um grande coágulo que posteriormente se desintegra aos poucos. Com outras fontes protéicas esse fenômeno não ocorre. Logo, a natureza da proteína utilizada nos sucedâneos é importante, pois, conforme o tipo de proteína, a consistência do coágulo diminui acentuadamente.

A caseína do leite tem propriedade única de se coagular no abomaso na presença de renina. Desta forma, o bezerro, apesar de mamar apenas duas a três vezes por dia, tem um suprimento contínuo de proteína. Há aumento na quantidade e tipo de enzima produzida pelo aparelho digestivo dos bezerros, ao longo de seu desenvolvimento (ØRSKOV, 1992). A boa coagulação no abomaso influi positivamente na digestão da gordura que, retida em pequenas porções, permite uma ação mais prolongada da esterase pré-gástrica sobre os ácidos graxos e evita o processo de sensibilização provocado pela absorção, no intestino delgado, de moléculas protéicas não cindidas (STORRY E FORD, 1982; ROY et al., 1977). 


\section{CARACTERÍSTICAS DE UM BOM SUCEDÂNEO}

O nível de substituição do leite in natura em sistemas de aleitamento está agregado ao custo comparado do produto substituinte como substituto à base de leite de soja e soro de queijo (GERMANO, 1992; BARRETO, 1993; LOPES, 1996), ou colostro (in natura fermentado, congelado ou refrigerado) (FOLEY; OTTERBY, 1978).

O uso de sucedâneos pode diminuir o custo de produção, além de aproveitar ingredientes pouco usados ou impróprios para o consumo humano (SUSIN et al., 1988). No entanto, o desempenho de terneiros alimentados com sucedâneos comumente é inferior em relação àqueles que recebem leite integral (LYNCH et al., 1978). Para minimizar estas diferenças, a sua composição deve aproximar-se da do leite integral (OTTERBY; LINN, 1981). Segundo o NRC (2001), são recomendados como níveis mínimos $22 \%$ de proteína bruta, $10 \%$ de extrato etéreo, $0,70 \%$ de cálcio e $0,60 \%$ de fósforo. Os sucedâneos podem causar problemas quando apresentam excesso de amido e fibra, baixa qualidade e inadequada incorporação das gorduras e fontes protéicas de baixo aproveitamento ou que provocam transtornos digestivos (LOPES et al., 1998).

Os maiores problemas a serem contornados quando se procura substituir o leite por outro alimento, em idade precoce, são: ausência de sistemas enzimáticos capazes de hidrolisar outro carboidrato que não seja lactose; outros lipídeos que não sejam os da gordura do leite (ácidos graxos de cadeia curta); a necessidade fisiológica de uma proteína que, tal como a caseína, propicie a formação de um coágulo de boa consistência no abomaso (OLIVEIRA, 2007), além da presença de fatores antinutricionais (DAVIS; DRACKLEY, 1998). 


\section{SORO DE QUEIJO IN NATURA COMO SUBSTITUTO DO LEITE INTEGRAL NO ALEITAMENTO DE BEZERROS}

Os alimentos protéicos para o gado podem originar-se de várias fontes. Dentre as de origem animal encontra-se o soro de queijo, que pode ser ministrado na forma líquida ou desidratado.

O soro de queijo é um subproduto de importância relevante, tendo em vista o volume produzido e sua composição nutricional. É um produto resultante da precipitação de gorduras e caseína do leite durante a fabricação do queijo. Este produto representa de 85 a $90 \%$ do volume de leite e retém $55 \%$ de seus nutrientes, dentre eles a lactose ( 4 a 5\%) e proteínas $(0,6$ a 0,7\%) (ALMEIDA et al., 2001).

É constituído basicamente de água (93\%) e somente $7 \%$ de matéria seca (parte sólida), do qual $71 \%$ são lactose, $10 \%$ são proteína bruta (PB), $12 \%$ são gordura e $11 \%$ são sais minerais. O valor energético do soro do queijo é estimado em $80 \%$ de nutrientes digestíveis totais (NDT), na matéria seca (LIZIEIRE; CAMPOS, 2006).

No entanto é preciso adiantar que a substituição total do leite por soro é impossível. Embora o soro seja derivado do leite, sua composição é totalmente distinta, não permitindo a correta nutrição de bezerras em fase de amamentação. Uma das diferenças é que o soro possui alto valor energético oriundo de uma alta concentração de lactose (65-70\% da matéria seca). 0 excesso de lactose provoca diarréia em bezerros (por fermentar no intestino) o que, por si só, já impediria a substituição completa do leite. Esta possibilidade de diarréia é agravada pela alta concentração mineral (desbalanceada) em sua composição (PEREZ, 2002). MONTENEGRO et al., (1998) relata que a substituição de até $60 \%$ do leite bovino por soro de queijo não afetou o desenvolvimento de pequenos ruminantes, LIMA et al., (2011) também não observaram influencia no desenvolvimento de bezerros recebendo soro de queijo e desmamados aos 60 dias, FONTES et al., (2006) ao avaliarem desempenho de bezerros alimentados com sucedâneo a base de soro de queijo 
LIMA, R.N. et al. Utilização de soro de queijo in natura no aleitamento de bezerros: uma alternativa viável. PUBVET, Londrina, V. 6, N. 34, Ed. 221, Art. 1468, 2012.

observaram que a substituição em até $64,4 \%$ do leite por soro não afetou o desempenho dos animais. Já Lima et al. (2012) avaliando a associação do soro de queijo ao colostro (70 e 30\%) obtiveram resultados semelhantes aos obtidos com leite integral.

As proteínas do soro de leite têm alto valor biológico, e sua utilização na alimentação humana e animal permite, ainda, a redução da liberação de resíduos poluentes no meio ambiente e o aumento na margem de lucratividade da indústria (FONTES et al, 2006). No entanto o baixo teor protéico do soro de queijo é insuficiente para atender às exigências de bezerros recém-nascidos, muito embora a digestibilidade desta proteína seja semelhante à da caseína, a proteína do leite (PEREZ, 2002). Assim, torna-se necessário dar uma atenção ao concentrado fornecido ao bezerro junto com o soro de queijo para se necessário fazer-se uma suplementação protéica.

Quanto à utilização de soro na dieta, o fornecimento deve ser regular, ininterrupto e os animais necessitam de um período de adaptação, com duração de uma a duas semanas, aumentando-se gradativamente a quantidade oferecida, para evitar diarréias e timpanismo, permitindo que a microflora do rúmen se ajuste a este novo alimento (LIZIEIRE; CAMPOS, 2006).

A utilização de soro de leite permite bons desempenhos, em função de seu adequado perfil de aminoácidos e ausência de fatores anti-nutricionais (DAVIS E DRACKLEY, 1998). Entretanto, o soro não deve substituir o leite ou o sucedâneo de leite na fase de cria por não conter os nutrientes necessários, principalmente proteína, para garantir sozinho o desenvolvimento dos animais nesta fase. Dentre os nutrientes a serem supridos, a proteína tem recebido especial atenção por ser exigida em quantidades relativamente altas e ser de elevado custo (BONA FILHO et al., 1992).

Devido à grande disponibilidade do soro de queijo in natura, bem como seu oferecimento gratuito ou a baixo preço, muitos produtores o têm fornecido indiscriminadamente aos animais, especialmente na alimentação de suínos e do gado leiteiro adulto. Por ser um alimento rico em nutrientes e não contem 
fatores antinutricionais, este produto apresenta amplas possibilidades na alimentação animal visando redução de custos. Um entrave, porém, consiste na necessidade de suplementar a proteína (caseína), coagulada na fabricação do queijo, para animais muito jovens, devido a uma série de limitações fisiológicas destes em relação a outras fontes de proteína.

\section{CONSIDERAÇÕES FINAIS}

Considerando-se que a substituição do leite por soro não prejudica o desenvolvimento corporal dos animais após a fase de cria, a sua inclusão na alimentação pode ser bastante vantajosa sob o ponto de vista econômico.

\section{REFERÊNCIAS BIBLIOGRÁFICAS}

ALMEIDA JÚNIOR, G.A.; COSTA, C.; CARVALHO, S. M. R.; PERSICHETTI JÚNIOR, P.; PANICHI, A. Composição físico-química de carcaças de bezerros holandeses alimentados após o desaleitamento com silagem de grãos úmidos ou grãos secos de milho ou sorgo. Revista Brasileira de Zootecnia, v.37, n.1, p.164-170, 2008.

ALMEIDA, K. E.; BONASSI, I. A.; ROÇA, R. O. Características físicas e químicas de bebidas lácteas. Ciência e tecnologia de alimentos, Campinas, v.21, n.2, p. 187-192, maio. 2001.

ANTUNES, L. M.; ENGEL, A. Manual de administração rural: custo de produção. 3. ed. São Paulo: Guaíba Agropecuária, 1999. 196p.

BARRETO, L. C. N. Utilização de misturas de "leite" de soja esoro de queijo no aleitamento de bezerros.1993. 51f. Dissertação (Mestrado em Zootecnia) - Universidade Federal de Lavras, Lavras, 1993

BATH, L.; DICKINSON, F. N. et al. Dairy Cattle: principles practices, problemsprofits. 3. ed. Philadelphia: Lea\&Febiger, 1985. p. 473.

BERMUDES, R. F., PEIXOTO, R. R. Avaliação do farelo de arroz na alimentação de bezerros da raça Holandês. Revista da Sociedade Brasileira de Zootecnia, Viçosa, v. 26, n. 2, p. 391395, maio. 1997

BONA FILHO, A. F., OTTO, C., LEME, M. C. J. Ganho de peso e características de carcaças de cordeiros confinados e suplementados com diferentes níveis de farinha de peixe. Agrárias, 13 (1): 1992, p. $183-191$.

CAMPOS, O. F.; LIZIEIRE R. S. Alimentação de bovinos jovens. Belo Horizonte: UFMG, 1995. (Cadernos Técnicos, 14). 
CAMPOS, O. F.; LIZIEIRE R. S. Desaleitamentoprecoce e alimentação de bezerras. In: SIMPÓSIO SOBRE MANEJO E NUTRIÇÃO DE GADO DE LEITE, 1., 2000, Goiânia, Anais... Goiânia, GO: Colégio Brasileiro de Nutrição Animal, 2000. p.1-20

CAMPOS, O. F.; LIZIERE, R. S.; DERESZ, F. Sistemas de aleitamento natural controlado ou artificial. II Efeito na performance de bezerros mestiços holandês - zebu. Revista da Sociedade Brasileirade Zootecnia, Viçosa, v. 22, n. 3, mar. 1993.

CANZINI, J. R. F. Uma abordagem sobre as diferenças de metodologias utilizadas no cálculo do custo total de produção da atividade leiteira a nível individual (produtor) e a nível regional. In: SEMINÁRIO SOBRE METODOLOGIAS DE CÁLCULOS DO CUSTO DE PRODUÇÃO DE LEITE, 1., Piracicaba, 1999, Anais...Piracicaba:USP, 1999.

CARDOSO, V. L.; NOGUEIRA, J. R.; VERCESI FILHO, A. E.; FARO, L. E.; LIMA, N. C. Objetivos de seleção e valores econômicos de características de importância econômica para um sistema de produção de leite a pasto na Região Sudeste. RevistaBrasileira de Zootecnia, Viçosa,v.33, n.2, p.320-327, mar. 2004.

CARVALHO, L. A. et. al. Sistema de produção de bovinos de leite (Cerrado). Juiz de Fora: Embrapa Gado de Leite, 2002. Disponível em: <http://www.cnpgl.embrapa.br/>. Acesso em: 30 abr. 2009.

COELHO, S. G. Criação de Bezerros. In: SIMPÓSIO MINEIRO DE BUIATRIA, 2., 2005, Belo Horizonte. Anais... 2005.

D'AVILA, D. Uso do aleitamento exclusivo com sucedâneo lácteo por 14 dias e de mistura iniciadora especial no desenvolvimento corporal de bezerros holandês. 2006. 86f. Dissertação (Mestrado em Zootecnia) - Universidade Federal do Rio Grande do Sul, Porto Alegre - RS.

DAVIS, C. L.; DRACKLEY, J. K.The development, nutrition and management of the young calf.Iowa: StateUniversity, 1998. 339p

FARIA, V. P. Produção leiteira de bezerras e novilhas a partir da dieta. RevistaBaldeBranco, São Paulo, v. 31, n. 367, p. 24-29, out. 1995

FOLEY, J. A.; OTTERBY, D. E. Availability, storage, treatment, composition, and feeding value of surplus colostrum: a review. J. Dairy Sci., Savoy, v. 61, n. 5, p.1033-1060, aug. 1978.

FONTES, F. A. P. V. et. al. Desempenho de bezerros alimentados com dietas líquidas à base de leite integral ou soro de leite. Arq. Bras. Med. Vet. Zootec., Belo Horizonte, v.58, n.2, p.212-219, mar. 2006

GERMANO, J. L. Utilização de substitutos de leite a base desoja e soro de queijo na alimentação de bezerros. 1992. 91f. Dissertação (Mestrado em Zootecnia) - Universidade Federal de Lavras, Lavras, 1992.

HEINRICHS, A. J.; Jones, C.M. 2003.Feeding the newborn Dairy calf. Pennsylvania, U.S.A., The Pennsylvania State University. College of Agricultural Sciences.AgriculturalResearchandCooperativeExtension.

HOFFMANN, R.; ENGLER, J. S.; SERRANO, O. Administração da empresa agrícola. 5. ed. São Paulo: Pioneira, 1987. 325 p. 
KOLB, E., GURTLER, H., KETZ, H, A., SCHRODER, L. \& SEIDELL, H. Fisiologiaveterinária. 4. ed. Rio de Janeiro: Guanabara, 1984.

KROHN, C.C. Effects of different suckling systems on milk production, udder health, reprodution, calf growth and some behavioural aspects in high producing dairy cows - a review. Applied Animal Behaviour Science, v. 72, n. 3, p. 271-280, 2001.

Lima, R.N.; Lima, P.O.; Aroeira, L.J.M. et al. Desempenho de bezerros aleitados com soro de queijo em associação ao colostro. Pesquisa agropecuária brasileira, v.47, n.8, p.11741180, ago. 2012.

LIMA, R. N.; LIMA, P. O.; CÂNDIDO, M. J. D.; PONTES, F. S. T.; MOREIRA, R. H. R.; AQUINO, R. M. S. Avaliação econômica de dietas líquidas à base de soro de queijo in natura para bezerros. Revista Brasileira de Saúde e Produção Aninal, Salvador, v.12, n.1, p.14-21 jan/mar, 2011.

LIZIEIRE, R. S.; CAMPOS, O. F. Soro de queijo "in natura" na alimentação de gado de leite. 2006.Disponível em: <http://www.embrapagadodecorte - pasta do produtor -folha 46. htm>Acesso em: 15 maio. 2009.

LIZIERE, R.S.; CAMPOS, O. F. Alimentação de Bezerros. Inf. Agrop., Belo Horizonte, v. 16, n. 175 , p. 32 - 36, mar. 1992.

LOMBARDI, C. T.; CASTRO, A. C. G.; SILVA, J. F. C. da; PEREIRA, J. C.; VALADARES FILHO, S. de C.; CECON, P. R. Desempenho de bezerros desaleitados precocemente submetidos a restrição no fornecimento do leite. In: REUNIÃO ANUAL DA SOCIEDADE BRASILEIRA DE ZOOTECNIA, 34., 1997, Juiz de Fora. Anais... Juiz de Fora, MG: SBZ, 1997. p. 227-229.

LOPES, J. N. P., CAMPOS, O. F. DE, LEÃO, M. I. et al. Efeito de dietas líquidas à base de leite integral e, ou, subprodutos de soja sobre algumas características relacionadas à digestão, em bezerros. Revista da SociedadeBrasileira de Zootecnia, Viçosa, v. 27, n. 3, p. 603-612, mar. 1998.

LOPES, M. A.; CARVALHO, F. M. Custo de produção do leite. Lavras: UFLA, 2000. 42p. (Boletim Agropecuário, 32).

LUCCI, C. S. Manejo de novilhas. Revista a Raça Jersey, São Paulo, v.1, n.3, p.40-43, maio. 1992.

LYNCH, G. P., PIKE, T. L., BOND, J. Nutritional responses of calves fed milk or a milk replacer. Journal of DairyScience, v. 61, p. 212-220, 1978.

MODESTO E. C.; MANCIO, A. B.; MENIN, E.; CECON, P. R.; DETMANN, E. Desempenho produtivo de bezerros desmamados precocemente alimentados com diferentes dietas líqüidas com utilização de promotor de crescimento. Revista Brasileira de Zootecnia, v.31, n.1, p.429-435, 2002 (suplemento).

MONTENEGRO, M. P.; AZEVEdo, A. R.; BARROS, N. N.; PIMENTEL, J. C. M.; ALVES, A. A. Uso do Soro de Queijo de Cabra no Aleitamento Artificial de Cabritos. Revista Brasileira de Zootecnia, v.27, n.6, p.1212-1217, 1998.

NATIONAL RESEARCH COUNCIL - NRC. Nutrients requirements of dairy cattle.7.ed. NationalAcademyPress, Washington, D.C., 2001. 381p 
OLIVEIRA, J. S.; ZANINI, A. M.; SANTOS, E. M. Fisiologia, manejo e alimentação de bezerros de corte. Arq. Ciênc. Vet. Zool. Unipar, Umuarama, v. 10, n. 1, p. 39-48, 2007.

ORSKOV,E.R.Alimentacióndelosruminantes.Acríbia, Zaragoza,1990.p.10.

ØRSKOV, E.R.Protein nutrition in ruminant. Aberdeen: Academic Press, 1992. 175p.

OTTERBY, D. E.; LINN, J. G. Advances in nutrition and management of calves and heifers.JournalofDairy Science, v. 64, n. 6, p. 1365-1377, 1981.

PERES, J. R. Soro de Leite na Alimentação de Bezerras. 2002. Disponível em: < http://www.milkpoint.com.br >. Acesso em: 15 maio. 2009.

REIS, R. P. Introdução à teoria econômica. Lavras: UFLA/FAEPE. 108p. 1999.

ROCHA, E. de O.; FONTES, C. A. de A.; PAULINO, M. F.; PEREIRA, J. C.; LADEIRA, M. M. Influência da idade de desmama e de início do fornecimento de volumoso a bezerros sobre a digestibilidade de nutrientes e o balanço de nitrogênio, pós-desmama. Revista Brasileira de Zootecnia, Minas Gerais, v.28, p.143-147, 1999.

ROY, J.H.B.; STOBO, I.J.F.; SHOTTON, S.M. et al.The nutritive value of non-milk proteins for the preruminant calf.The effect of replacement of milk protein by soy-bean flour or fish-protein concentrate.British JournalofNutrition, London, v.38, n.2, p.167-187, Sept. 1977.

SALLES, M. S. V.; ZANETTI, M. A.; CONTI, R. M. C; LIMA, C. G. Efeitos da monensina no desempenho de bezerras leiteiras em crescimento. RevistaBrasileira de Zootecnia, Viçosa, v.30, n.4, p.1293-1298, 2001.

STORRY, J.E.; FORD, G.D. Some factors affecting the post clotting development of coagulum strength in renneted milk. Journal of Dairy Research, Cambridge, v.49, n.3, p.469-477, Aug. 1982.

SUSIN, I., NETO, R. M., PIRES, A. V. et al. Desempenho de bezerros submetidos a diferentes dietas líquidas e períodos de aleitamento. Revista da SociedadeBrasileira de Zootecnia, Viçosa, v. 17, n. 1, p. 108-114, abr. 1988.

TEIXEIRA, J. C. et. al. Aproveitamento do macho leiteiro utilizando dietas à base de amirea 45s. II Desempenho. Ciênc. Agrotec., Lavras, v. 24, n. 1, p.203-207, mar. 2000.

THALER NETO, A.; GOMES, I. P. O.; Danielli, L. M. ; MEDEIROS, L. A.; SEMMELMANN, C. E. N. Avaliação de sucedâneos do leite com diferentes níveis de gordura para bezerros leiteiros. In: REUNIÃO ANUAL DA SOCIEDADE BRASILEIRA DE ZOOTECNIA, 45., 2008, Lavras - MG. Anais... Lavras - MG: Sociedade Brasileira de Zootecnia, 2008.

VASCONCELOS, M. A. Desempenho de bezerros da raça holandesa nascidos durante o período outono/inverno submetidos a diferentes dietas líquidas e instalações. 1996. 81 f. Dissertação (Mestrado em, Zootecnia) - Universidade Federal de Santa Maria, Santa Maria, 1996.

YAMAGUCHI, L. C. T. Custo de produção de leite: critérios e procedimentos metodológicos. In SEMINÁRIO SOBRE METODOLOGIAS DE CÁLCULOS DO CUSTO DE PRODUÇÃO DE LEITE, 1., 1999. Piracicaba, SP. Anais... Piracicaba: USP, 1999, São Paulo - SP. 